\title{
Growth aspects of the marine microalga Nannochloropsis gaditana
}

\author{
Jorge M.S. Rocha*, Juan E.C. Garcia, Marta H.F. Henriques \\ Chemical Engineering Department, University of Coimbra, 3030-290 Coimbra, Portugal
}

\begin{abstract}
Nannochloropsis is well appreciated in aquaculture due to its nutritional value and the ability to produce valuable chemical compounds, such as pigments (zeaxanthin, astaxanthin...) and polyunsaturated fatty acids (EPA). Commercial exploitation needs high cell densities but the low growth rate and the small size of cells are practical difficulties. To increase biomass concentration the positive effect of several factors was evident: (i) $\mathrm{pH} \approx 8$ control (with dilute Tris- $\mathrm{HCl}$ buffer); (ii) the continuous illumination (no evidence of photo-inhibition was observed); (iii) a quite large temperature range $\left(25 \pm 5^{\circ} \mathrm{C}\right)$; (iv) the presence of organic carbon source (with the danger of contamination); (v) the presence of urea as an additional nitrogen source (10 mM); (vi) a small air flow rate with large bubbles can be more efficient for $\mathrm{CO}_{2}$ mass transfer (associated to reduced shearing).
\end{abstract}

(C) 2003 Elsevier B.V. All rights reserved.

Keywords: Nannochloropsis; Microalgae; Culture conditions

\section{Introduction}

Some microalgae strains are recognised as excellent sources of proteins, carbon hydrates, lipids, and vitamins, to be used as food and feed additives, for more than 40 years [1,2]. The main constraint of artificial cultivation is the low biomass concentration achieved, c.a. $0.1 \%(\mathrm{w} / \mathrm{w})[3]$, which makes the separation process difficult and expensive. However, the importance of microalgae in aquaculture is large because they start the food chain. The nutritional value, related to the biochemical composition, makes Nannochloropsis well appreciated for feeding rotifers and fish hatcheries. Several species of Nannochloropsis were identified [46] since the genus was first presented [7]. Nannochloropsis is well known as a source of different valuable pigments, such as chlorophyll a, zeaxanthin, canthaxanthin and astaxanthin [8], produced at high levels. Nannochloropsis is also recognised as a good potential source of EPA (20:5 103$)$, an important polyunsaturated fatty acid for human consumption for prevention of several diseases [9]. That strain is not a self protected one, in contrast to Spirulina and Dunaliella, respectively

\footnotetext{
* Corresponding author. Tel.: +351-23-979-8731; fax: +351-23979-8703.

E-mail address: jrocha@eq.uc.pt (J.M.S. Rocha).
}

controlled by $\mathrm{pH}$ and ionic strength, because it grows in mild conditions. Although extensively grown in outdoor open ponds, these culture systems suffer several limitations. First, it is difficult to prevent bacterial contamination, competition with other microalgae and predation by protozoa. The use of chlorination, antibiotics or herbicides to maintain the cultures free of contamination, is not adequate to the pharmaceutical potential use of the metabolites produced by microalgae. Second, the lack of control of culture parameters, in particular irradiance and temperature, and third, the low cell density that is possible to achieve. To overcome these difficulties some closed photobioreactors have been proposed, either tubular type [10] or flat panel type [11]. The culture conditions, the nutrient needs and the hydrodynamics for a good mass transfer in reactors are not yet optimised, either for cell growth or metabolite production rates.

The effect of light-path length on cell biomass cultivation and EPA output rates [12], as well as the effect of cell density in photoacclimation [13] have been studied. The metabolism of pigments, chlorophyll in particular, is very dynamic in Nannochloropsis. There is an evidence that rapid changes in pigments (eventually other compounds) contents may be an adaptative response of cells to changes in light environment [14]. Another important problem, particularly in scaling up, 
is cell damage due to shear stress in sparged microalgae cultures, and lethal events associated $[15,16]$.

To follow microalgae growth, directly or indirectly, is always difficult because both the cell compound to quantify and the moment of sample collection, affect cell density estimation. These problems increase with dilute cultures and with small size cells, like the ones from Nannochloropsis $(2-4 \mu \mathrm{m})$. Evaluation by cell counting and by biomass dry weight is here presented and discussed. The effect of culture conditions on cell growth rate, in particular the nitrogen source, is studied, as well as the eventual double role of the specific surface area at the air/water interface.

\section{Materials and methods}

Nannochloropsis gaditana strain was obtained from the University of Huelva (Spain). The culture medium was the $\mathrm{f} / 2$ medium for marine algae [17], lightly modified (without trace vitamins stock solution). The growth was autotrophic being the inorganic $\mathrm{CO}_{2}$ from the atmosphere the unique carbon source, that reached the culture through a cotton rubber or by bubbling. A few experiments were done with mixotrophic growth, by adding glucose as organic carbon. The $\mathrm{f} / 2$ medium has a low concentration of $\mathrm{KNO}_{3}$ as nitrogen source $(0.75$ $\mathrm{mM})$. The same concentration of several nitrogen sources was added to $f / 2$ medium for studying their effect on cell growth. Sensitive compounds (e.g. urea, glycin) were sterilised by filtration, to avoid degradation.

Most of the cultures were done in Erlenmeyer flasks, with a cotton rubber, manual stirring twice a day, room temperature and natural sun light. The following variations were included:

i) air flow through a sparger plunged in the culture; however, at a small scale, culture losses by water evaporation and by cell dragging are significant and so, the experiments in those conditions are not reported here;

ii) immersion of the culture flask in a water bath with temperature control (with the disadvantage of light intensity attenuation through the water); however, lab room temperature was quite stable and suitable for cell growth;

iii) artificial light with tungsten lamp $100 \mathrm{~W}, 20 \mathrm{~cm}$ away from the flasks, with light/dark cycles $(12 \mathrm{~h} / 12$ h); light intensity received by the culture was not measured but was kept as constant as possible for different assays.

Another experimental apparatus for microalgae growth included two tubular bubble reactors (glass tubes with $70 \mathrm{~cm}$ high and $5 \mathrm{~cm}$ diameter), one of them with an aquarium sparger and the other with a capillary tube, for the air flow rate supply. Artificial illumination was carried out with fluorescent lamps 0.5 $\mathrm{m}$ away, more adequate to continuous illumination (to avoid culture heating). Illumination conditions were kept constant for each set of experiments reported.

For cell density evaluation, the number of cells was quantified by using a counting chamber (haemocytometer). The biomass dry weight was obtained after filtration with a $0.2 \mu \mathrm{m}$ membrane average pore and dried in an oven until constant weight. The optical density of the culture was evaluated by using a spectrophotometer, at $\lambda=540 \mathrm{~nm}$.

\section{Results and discussion}

\subsection{Evaluation of cell density}

Cell direct counting is a relatively precise method but time consuming. A turbidimetric method, like the optical density, is very practical and easy to use. However, absorbance being related to the amount of matter, also depends on the size and shape of suspended particles, their opacity, wavelength of incident light, etc. A calibration curve of cell number versus optical density is very useful for practical application. Apart the difficulties associated to cell counting, the relationship between cell number and optical density is very dependent on culture conditions, namely the illumination, culture media, $\mathrm{CO}_{2}$ supply, cell age, etc. In fact, the size and weight of each cell is not always the same. Consequently, a linear proportionality can only be found in the cell exponential phase, as shown in Fig. 1 (left graph). The absorbance measurement at $540 \mathrm{~nm}$, not corresponding to a maximum absorption peak, has the advantage of being not so sensitive to culture conditions changes or absorption shifts.

Another useful method for cell density quantification is the gravimetric method, by cell dry weight determination. With marine microalgae it can be affected by the amount of salts absorbed on the cell surface and present in intercellular water [18]. In some cases, the non cellular suspended solids, such as calcium carbonate, can affect the results but a suitable cell washing will reduce the problem. The application to cells of small size implies the use of large amounts of culture volumes and high cell density, in order to obtain a reproductive dry weight, that makes filtration difficult (loss of cells must be avoided) and time consuming. Once again, a calibration curve of cell dry weight versus optical density is very useful because absorbance is very easy to read. In this case the different culture conditions did not affect the linear proportionality, as shown in Fig. 1 (right graph). 

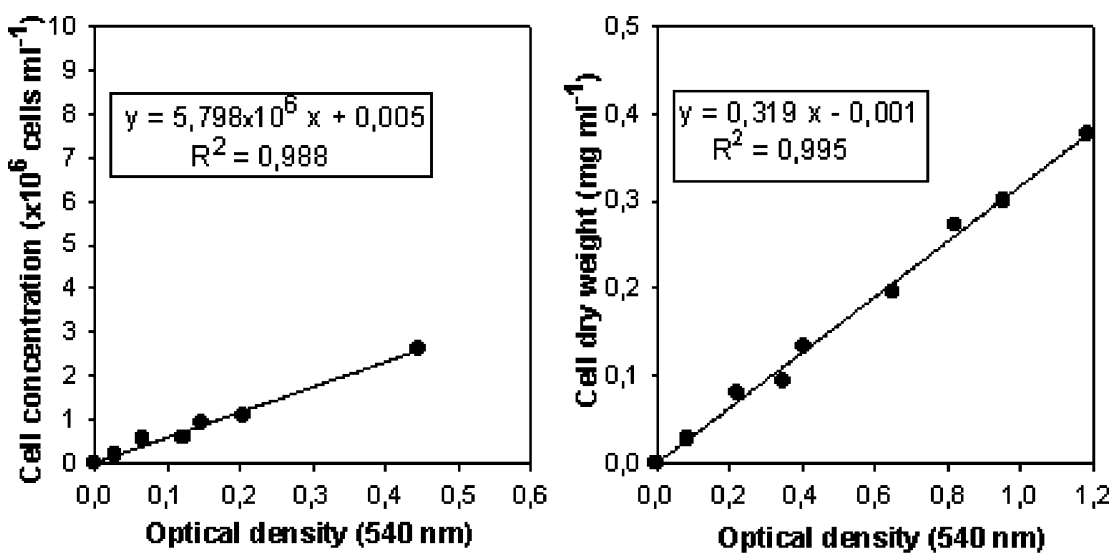

Fig. 1. Calibration curves. Left graph: cell concentration versus optical density (540 nm); right graph: cell dry weight versus optical density (540 $\mathrm{nm})$.

Both methods referred above (direct cell counting and biomass dry weight evaluation) in addition to calibration curves with optical density, are suitable for Nannochloropsis cell density evaluation and less dependent of light cycle, when compared to the quantification of only one component of the cell (protein, pigment,...). It was observed that cell dry weight evaluation is less sensitive to the physiologic state of the cell than direct counting, but a calibration curve is essential for fast routine assays.

\subsection{Cross effect of $\mathrm{pH}$, light conditions and temperature}

In Nature, the microalgae growth does not wonder about kinetics, being the growth rate just the enough one for species survival. Like any other species, the multiplication rate is highly dependent on environmental conditions, which are not constant in time being dependent of several factors. On the other hand, in artificial microalgae cultivation the goal is to favour the increasing of growth rate as much as possible or to push the metabolic route to follow one direction, if a particular metabolite has to be obtained. Looking microalgae as biocatalysts, a deeper control is necessary to achieve the productivity objectives and this can only be done in photobioreactors. The number of variables that affect microalgae growth rate is huge, with direct, indirect and cross-effect influences. For that reason the optimisation of the growth rate is always a difficult task for each species.

The experiments reported in this work were done for checking the effect of some variables and factors, under observation. The absolute values achieved for cell densities are not too high because it was not possible to set and to keep the optimum value of other variables that also affect the growth rate.

An important variable that affect Nannochloropsis growth rate is the $\mathrm{pH}$ value, as shown in Fig. 2 . Microalgae are sensitive to $\mathrm{pH}$ changes [19], being its control essential for keeping high growth rates. As microalgae are able to metabolise the inorganic carbon $\mathrm{CO}_{2}$, there is an equilibrium trend for the $\mathrm{pH}$ to increase. Its control can be done by using buffers or by the addition of $\mathrm{CO}_{2}$ (also used as carbon source) or inorganic acids. $\mathrm{pH}$ control is not very difficult to achieve and it can also help to preserve a pure culture. In Fig. 2 a positive effect of Tris- $\mathrm{HCl}$ buffer $(40 \mathrm{mM})$, keeping a constant $\mathrm{pH} 8$, on the growth rate was observed. On the 13th day, in the culture medium with distilled water, a mistake can be occurred during $\mathrm{pH}$ reading due to a time delay after harvesting the sample. The contact with atmosphere has probably saturated the mixture with $\mathrm{CO}_{2}$ and, consequently, the $\mathrm{pH}$ decreased. So, $\mathrm{pH}$ reading must be done immediately after sample harvesting. The kind of buffer to use is not only dependent on the $\mathrm{pH}$ range of interest but also taking into account the interference with other medium components. In the case of Nannochloropsis, phosphate buffer could not be used because it clouded the culture medium. A turbid medium makes difficult the light to get inside and makes impossible the use of the optical density method to follow the culture density.

Illumination (both natural and artificial) and temperature of microalgae cultures are very dependent variables. A strict control of both is difficult and expensive due to refrigeration needs. Mixing is the most practical way to dilute radiation evenly to all cells in the culture, improving the light regime [20]. This can be done by supplying an adequate air flow rate. Microalgae do not make a distinction between natural and artificial light, but they are much more sensitive to light intensity and light/dark cycles. An equivalent experiment to the one shown in Fig. 2, with artificial light/dark cycles, $12 \mathrm{~h}$ each, with a tungsten lamp $100 \mathrm{~W}$, $20 \mathrm{~cm}$ away from the flasks, instead of natural light (at Summer time day/night periods have similar length), gave identical results of growth rate. However, in this last case the temperature was higher $\left(30-35^{\circ} \mathrm{C}\right)$, because of the artificial light heating and the more difficult dissipation of energy to atmosphere. 


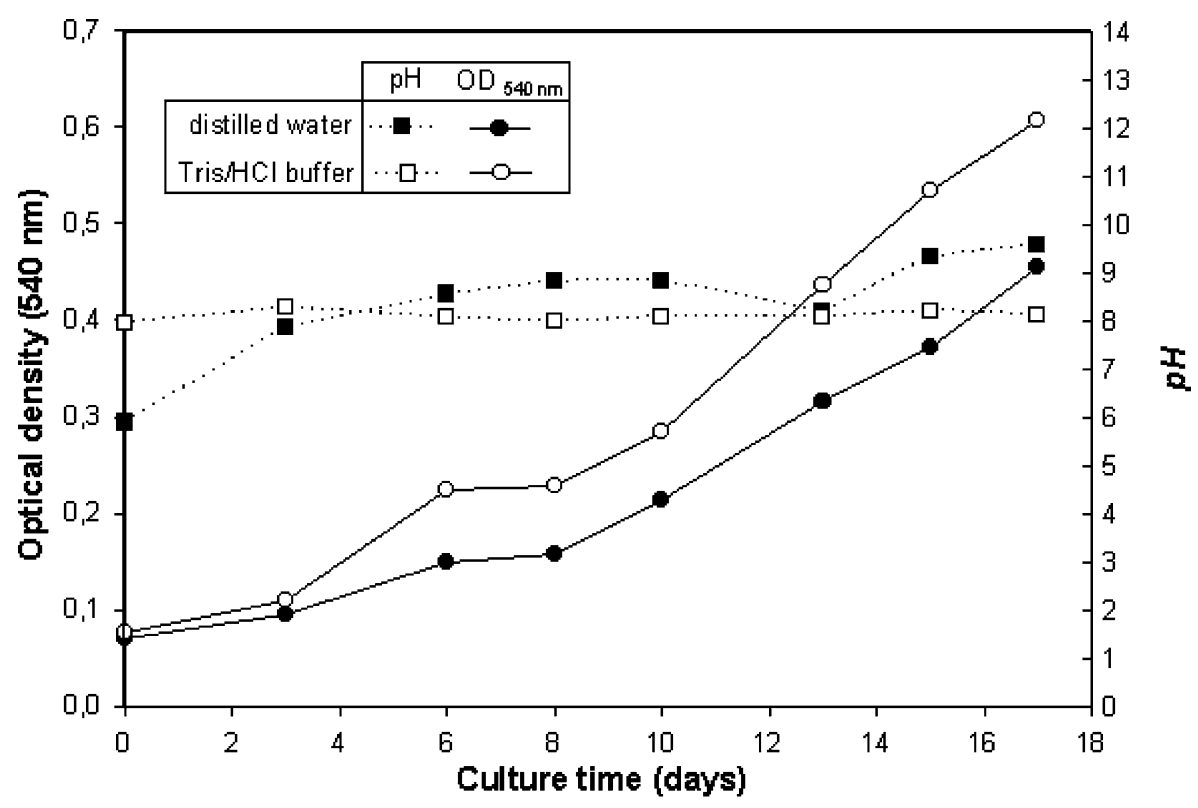

Fig. 2. Effect of Tris $-\mathrm{HCl}$ buffer on cell growth rate and on culture $\mathrm{pH}$ value. Culture in Erlenmeyers flasks with cotton rubber, indoors with natural illumination during Summer time, $T=25 \pm 2{ }^{\circ} \mathrm{C}$. ( $(\bigcirc)$ culture medium with distilled water; $(\bigcirc)$ culture medium with $\mathrm{Tris}-\mathrm{HCl}$ buffer $(40 \mathrm{mM})$.

On the other hand, with continuous illumination (only possible with artificial light) Nannochloropsis sp. growth was faster when compared to light/dark cycles, although the difference of temperature, $25 \pm 1{ }^{\circ} \mathrm{C}$ in the first case and $19 \pm 2{ }^{\circ} \mathrm{C}$ in the second one (Fig. 3). Nevertheless the culture conditions differences of both assays of Fig. 3 (namely temperature and illumination), we can observe good adaptation of this strain to continuous illumination, meaning that it will not be too sensitive to photo-inhibition. This does not mean it

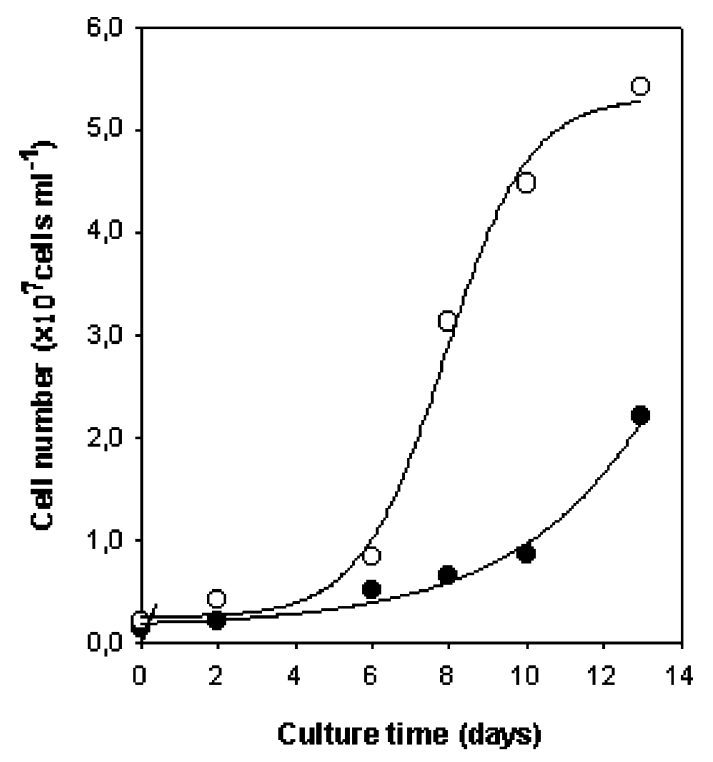

Fig. 3. Effect of illumination on the cell growth curve. Culture in Erlenmeyer flasks with cotton rubber, artificial light with tungsten lamp (100 W); (○) continuous illumination, ( $(\bullet)$ light/dark cycles (12 $\mathrm{h} / 12 \mathrm{~h})$. is not sensitive to light intensity, both to cell growth and to pigment production.

\subsection{Effect of additional nutrients}

The commonly used f/2 culture medium for Nannochloropsis sp. was shown to be limiting for both carbon and nitrogen sources. In fact, the medium has not carbon sources because autotrophic organisms are able to use the atmospheric $\mathrm{CO}_{2}$. However, the addition of small concentrations of glucose and ammonium sul-

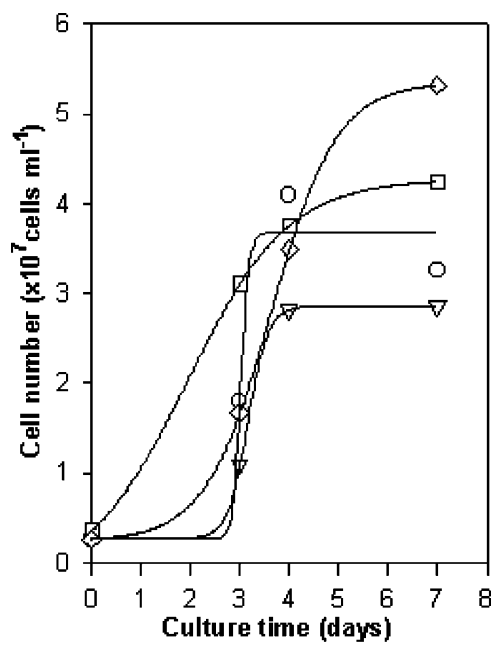

Fig. 4. Effect of additional carbon and nitrogen sources on cell growth rate (mixotrophic growth). Culture in Erlenmeyers flasks with cotton rubber, artificial light with light/dark cycles $(12 \mathrm{~h} / 12 \mathrm{~h}), T=19 \pm 2{ }^{\circ} \mathrm{C}$ (room temperature-Winter time). The following added concentrations $(\mathrm{mM})$ of glucose + ammonium sulphate, were respectively: $(\bigcirc)$ $5+5 ;(\nabla) 5+10 ;(\square) 10+5 ;(\diamond) 10+10$. 
phate increased the cell growth rate, as shown in Fig. 4. A disadvantage of using an organic carbon source is the higher probability of contamination with non-phototrophic bacteria. A combined effect of both carbon and nitrogen sources was observed because an increase in nitrogen concentration was only beneficial with a corresponding increase in carbon concentration. Because of practical and economic reasons, the inorganic $\mathrm{CO}_{2}$ from atmosphere must be the main carbon source to use in microalgae cultures. More attention can be devoted to nitrogen sources. The only nitrogen source present in $\mathrm{f} / 2$ medium is $\mathrm{KNO}_{3}$ with a low concentration $(0.75 \mathrm{mM})$. The effect of addition of different nitrogen sources $\left(\mathrm{KNO}_{3}, \mathrm{NaNO}_{3}, \mathrm{Ca}\left(\mathrm{NO}_{3}\right)_{2} \cdot 4 \mathrm{H}_{2} \mathrm{O}\right.$, urea and glycin; $10 \mathrm{mM}$ each) keeping constant the supply of atmospheric $\mathrm{CO}_{2}$ through the cotton rubber, was studied. Glycin and urea were sterilised by filtration, replacing the autoclave, to avoid degradation. Under the culture conditions used, only the addition of urea revealed an obvious positive effect on growth rate. The favourable effect of urea on cell growth rate was confirmed with another experimental apparatus (bubble column reactors) and with different culture conditions (continuous illumination), as shown in Fig. 5.

\subsection{Influence of air supply distribution}

The mass transfer of $\mathrm{CO}_{2}$ from air to the culture is facilitated by air bubbling inside the culture, when compared to the transfer rate that occurs just at the superficial interface air/culture (such as in Erlenmeyer flasks). Bubbling also promotes the stirring of the culture, which affects both the mass transfer of nutrients through the cell membrane and the light distribution, by the light/dark cycles inside the reactor. On the other hand, the sensitivity of different species to shear forces produced by gas bubbling is a main factor that affect algal growth [21] and must be taken into account. Cell fragility is even referred as a key problem in microalgae biomass production in photobioreactors [15]. Some authors [16] refer that sometimes cell sensitivity to shear forces is an easy way to explain the low productivities and growth rates in microalgae cultures. In fact, cells have the ability to adapt to stressing conditions. However, sheering effects were shown to be important, even to microalgae with cell wall, as described below.

Two different average air flow rates and two different ways of air distribution in bubble column reactors, for Nannochloropsis sp. growth, as shown in Fig. 6, gave different results from previously expected. For each air flow rate, from the sparger a large amount of fine bubbles were raised while the capillary tube originated a small number of large bubbles, which means a complete different hydrodynamic of the reaction mixture. Two apparently contradictory results can be observed from Fig. 6. First, to both types of air injection systems, a greater air flow rate per culture volume (vvm-volume of air per volume of culture and per min) resulted in a

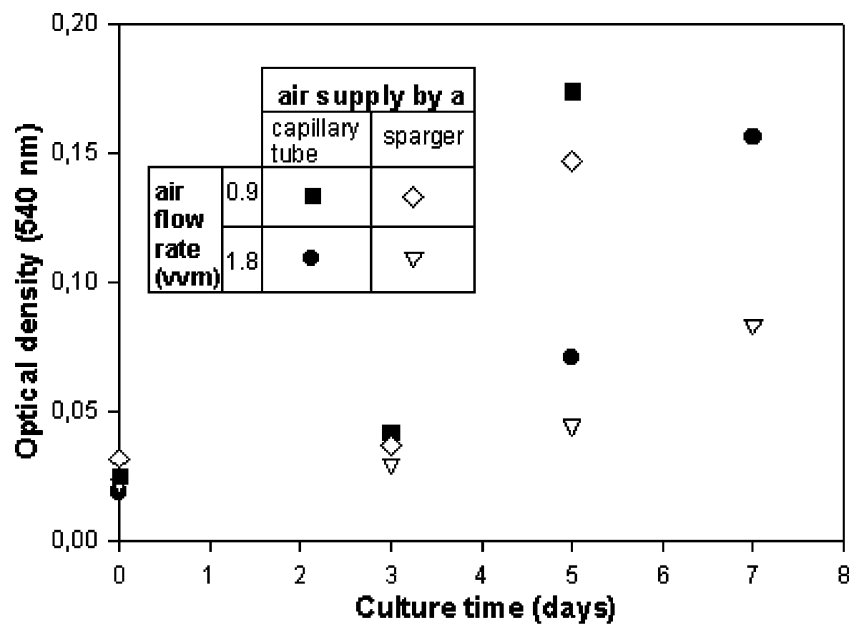

Fig. 6. Effect of air flow rate and type of sparger on cell growth curve. Cell culture in bubble column reactors, artificial light with light/dark cycles $(12 \mathrm{~h} / 12 \mathrm{~h})$, room temperature.

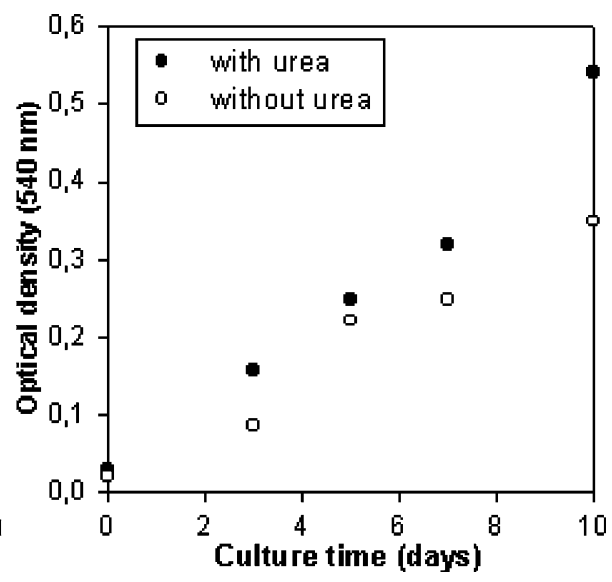

Fig. 5. Effect of additional urea $(10 \mathrm{mM})$ on cell growth rate. Culture in bubble column reactors, air flow rate c.a. 0.9 vvm, continuous illumination with fluorescent lamps. Left graph: air delivered by a capillary tube. Right graph: air delivered by an aquarium sparger. 
decreasing of cell growth rate. Second, to both air flow rates, the sparger led to a lower cell growth rate, although the air/liquid interfacial area per culture volume unit is much larger when compared to the few big bubbles formed with the capillary inlet of air. This experiment shows that a large specific (i.e., per culture volume unit) air flow rate, or a large specific air/water interfacial area, does not necessarily mean a high microalgae growth rate. In fact, apart the $\mathrm{CO}_{2}$ mass transfer rate (which theoretically would be favoured in both cases), there are also the shearing effects on the cells, accordingly the type of agitation induced. A maximum of the growth rate as a function of the aeration rate is also referred in literature for other microalgae species in bubble columns [22]. This is another example of cross-effect of different variables and explain why it is so difficult to optimise microalgae growth.

\section{Conclusions}

One of the main goals in artificial microalgae cultivation is to obtain high cell densities.

A calibration curve of cell number versus optical density is very useful for practical application. Apart the difficulties associated to cell counting, that relationship is very dependent on culture conditions. In fact, the size and the weight of each cell is not always the same. Consequently, a linear proportionality can only be found in the cell exponential phase.

The gravimetric method is time consuming and filtration is difficult, particularly for small cells and dilute cultures. The calibration curve of cell dry weight versus optical density is not affected by different culture conditions.

Nannochloropsis growth can be improved with a longer light period, a $\mathrm{pH}$ control and the addition of urea as an extra nitrogen source.

Air supply by bubbling leads to a high air/liquid interfacial area per culture volume, which favours the
$\mathrm{CO}_{2}$ mass transfer rate. However, shearing forces on the cells may have an adverse effect on the growth rate. In fact, the increase either on the specific air flow rate or on the specific interfacial area does not mean necessarily a real improve on cell growth rate, due to the opposite actions above referred. If this problem can be overcome by an increasing adaptation of cells to shearing stress conditions, still needs to be proved.

\section{References}

[1] Krauss R. Am J Bot 1962;49:425-35.

[2] Lopéz R. Grasas Aceites 1981;32:244-51.

[3] Shifrin NS, Chisholm SW. J Phycol 1981;17:364-84.

[4] Lubián LM. Lazaroa 1982;4:287-93.

[5] Karlson B, Potter D, Kuylenstierna M, Anderson RA. Phycilogia 1996;35:253-62.

[6] Anderso RA, Jacobson DM, Sexton JP. Catalog of Strains. Maine: West Boothbay Harbor, 1991:98.

[7] Hibbered DJ. Bot J Linnean Soc 1981;82:93-119.

[8] Lubián LM, Montero O, Moreno-Garrido I, Huertas IE, Sobrino C, González-del Valle M, Parés G. J Appl Phycol 2000;12:24955 .

[9] Sukenik A, Cohen Z, editors. Chemicals from Microalgae. cap 3, Taylor \& Francis; 1999.

[10] Zittelli GC, Lavista F, Bastianini A, Rodolfi L, Vincenzini M, Tredici MR. J Biotechnol 1999;70:299-312.

[11] Zittelli GC, Pastorelli R, Tredici MR. J Appl Phycol 2000;12:521-6.

[12] Zou N, Richmond A. J Biotechnol 1999;70:351-6.

[13] Zou N, Richmond A. J Appl Phycol 2000;12:349-54.

[14] Sukenik A, Carmeli Y, Berner T. J Phycol 1989;25:686-92.

[15] Gudin C, Chaumont D. Biores Technol 1991;38:145-51.

[16] Barbosa MJ, Albrecht M, Wijffels RH. Biotechnol Bioeng 2003;83:112-20.

[17] http://www.ife.ac.uk/ccap/mediarecipes2.html.

[18] Zhu CJ, Lee YK. J Appl Phycol 1997;9:189-94.

[19] Lee YK, Pirt SJ. J Chem Tech Biotecnol 1984;34B:28-32.

[20] Richmond A, Cohen Z, editors. Chemicals from Microalgae. cap 15, Taylor \& Francis; 1999.

[21] Suzuki T, Matsuo T, Ohtaguchi K, Koide K. J Chem Tech Biotechnol 1995;62:351-8.

[22] Mirón AS, Gómez AC, Camacho FG, Grima EM, Chisti Y. J Biotechnol 1999;70:249-70. 